\title{
Needling toward essential health benefits
}

$\mathrm{T}$

he era of acupuncture's existence as a practice on the margins of medicine appears to be inexorably drawing to a close.

Moves are afoot in California and Maryland to include acupuncture as an essential health service covered by insurance plans, while several other states have launched themselves along a similar trajectory.

In Canada, meanwhile, British Columbia has already made acupuncture a medically necessary service covered by its health care plan, while four other provinces are now regulating the practice. Canadian practitioners hope this is the first step toward acupuncture's inclusion in their provincial health plans, primarily as a treatment for pain and postoperative nausea, although they acknowledge that it may be some time coming.

The moves in California and Maryland are being undertaken under the rubric of reforms prompted by the federal Patient Protection and Affordable Care Act, the legislative foundation of United States President Barack Obama's overhaul of the American health care system. It requires all states to create "Affordable Insurance Exchanges" under which individuals and small businesses can buy basic health coverage.

To that end, states had to choose, before Sept. 20, a "benchmark" health plan that exchanges must meet or exceed. It had to offer a basket of health services in 10 areas, including chronic disease management, emergency services, maternity and newborn care, mental health and substance abuse services, prescription drugs, ambulatory care and rehabilitative care. Exchanges must adopt the essential health benefits specified by the benchmark by January 2014 .

In California, two different bills designating acupuncture as an essential health serviced now await Governor Jerry Brown's signature. If, as expected, he signs those bills into law, "it would guarantee at least a nominal level of access to acupuncture care" for almost all Californians, says Bill Mosca, executive director of the California State Oriental Medicine Association.

In Maryland, the benchmark plan was to be chosen from among six existing health insurance plans now offered to residents of the state, all of which contain acupuncture benefits. "Acupuncture will definitely be included - our state feels it meets the criteria for ambulatory services under the designations for EHB [essential health benefits]," Tracy Soltesz, president of the Maryland Acupuncture Society Inc., writes in an email.

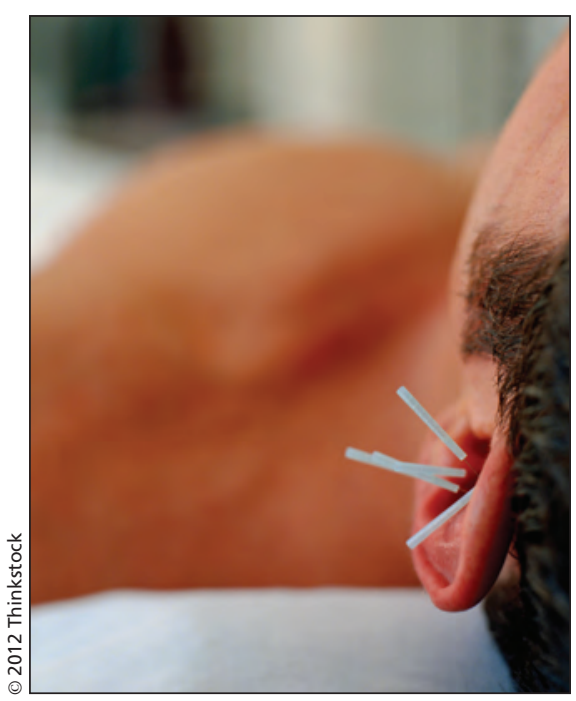

Acupuncture is often used as a treatment for pain and postoperative nausea.

The lobby to declare acupuncture an essential health service has been fierce, and nationwide. The American Association of Acupuncture and Oriental Medicine has focused its efforts on the United States Department of Health and Human Services, while the association's member organizations have targeted state legislators.

"Every state is working on it," says Michael Jabbour, a New York acupuncturist and president of the association, which contends that acupuncture is a more effective, less costly and less invasive procedure than many surgical and pharmaceutical options. Their position is bolstered by a recent meta-analysis which concluded that acupuncture worked better than standard treatment or placebo to relieve pain from chronic headaches, backaches and arthritis (http://archinte.jamanetwork.com/article .aspx?articleid=1357513).

In Canada, only $\mathrm{BC}$ reimburses acupuncture treatments under its provincial health insurance plan. While both physicians and non-physicians can practise as acupuncturists in Canada, only BC, Newfoundland and Labrador, Alberta, Quebec and Ontario regulate the profession.

Although most provinces are rushing to de-list rather than add services to their provincial health plans, complementary medical services such as acupuncture should be included on those lists if the evidence supports their use, according to experts like David Moher, a senior scientist at the Ottawa Hospital Research Institute in Ontario. "I don't think we should treat complementary medicine different than drugs, he says, adding that the benefit to patients should dictate coverage. "Drugs are not without harm and I'm really interested in what's out there for patients and consumers more generally," he says.

Canadian acupuncturists, though, do not appear to be pursuing inclusion as aggressively as their American counterparts. For example, while the College and Association of Acupuncturists of Alberta began regulating its profession last year, it has not yet sought coverage in the provincial insurance plan, says Registrar Paul Hu.

But if the provincial government "would provide even limited coverage for acupuncture services, that would be good. We would like it if in the future it would be covered by Alberta Health Services," he adds.

Historically, there has been animosity between medical and nonmedical practitioners over the use of acupuncture, says Dr. Linda Rapson, a physician who uses the alternative therapy at her pain clinic in Toronto, Ontario. But an increasing number of Canadians are turning to such therapies to treat chronic conditions and an increasing number of physicians are willing to refer patients for such treatment, she says.

"Rather than acupuncture being a last resort, if it were used more liberally, it would certainly put a dent in our health care budget in Canada," says Rapson, who is also executive president of the Acupuncture Foundation of Canada Institute. — Laura Eggertson, CMAJ

CMAJ 2012. DOI:10.1503/cmaj.109-4300 